\title{
Forensic Entomology
}

Carlos Henrique Marchiori ${ }^{1}$

1 Ins tituto Federal Goiano

Forensic Entomology - the study of insects and other arthropods associated with various criminal issues - serves as an auxiliary tool, for example, in investigating crimes against victims of violent death [ 